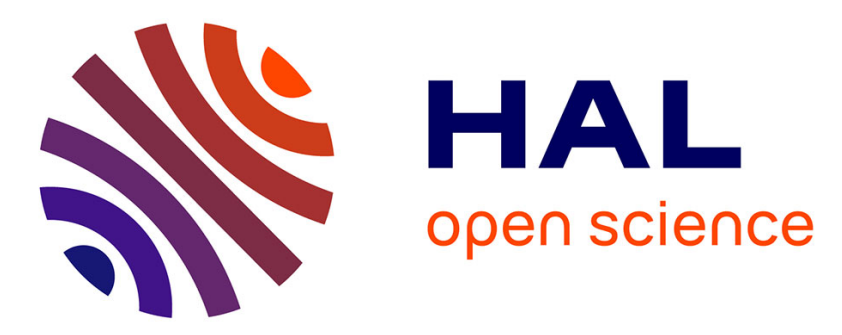

\title{
Simplifying OA Policy Compliance for Authors Through a Publisher- Repository Partnership
}

Mariya Maistrovskaya, Judy Hum-Delaney

\section{To cite this version:}

Mariya Maistrovskaya, Judy Hum-Delaney. Simplifying OA Policy Compliance for Authors Through a Publisher- Repository Partnership. ELPUB 2018, Jun 2018, Toronto, Canada. 10.4000/proceedings.elpub.2018.7 . hal-01816819

\section{HAL Id: hal-01816819 \\ https://hal.science/hal-01816819}

Submitted on 15 Jun 2018

HAL is a multi-disciplinary open access archive for the deposit and dissemination of scientific research documents, whether they are published or not. The documents may come from teaching and research institutions in France or abroad, or from public or private research centers.
L'archive ouverte pluridisciplinaire HAL, est destinée au dépôt et à la diffusion de documents scientifiques de niveau recherche, publiés ou non, émanant des établissements d'enseignement et de recherche français ou étrangers, des laboratoires publics ou privés. 


\title{
Simplifying OA Policy Compliance for Authors Through a Publisher- Repository Partnership
}

\author{
Mariya Maistrovskaya and Judy Hum-Delaney
}

\section{Background}

1 The Canadian Tri-Agency Open Access Policy on Publications (Government of Canada, 2015) in effect May 2015 presented federal grant recipients with a challenge of incorporating open access compliance into their research workflows. The policy requires that peer-reviewed articles arising from CIHR, SSHRC, or NSERC funding be made publicly available within 12 months of publication. Researchers have an option to comply by publishing in an open access or a hybrid journal or by depositing a copy of an article in an open access institutional or subject repository.

Despite increased outreach efforts and assistance provided by many Canadian academic libraries as well as Canadian not-for-profit publishers such as Canadian Science Publishing, compliance to the policy remains a challenge for researchers who are either unaware of the policy or unsure how to comply. Additional challenges for researchers stem from the fact that while the cost of open access publishing is an eligible grant expense, many grantees do not receive enough funding to cover author processing charges, particularly where multiple publications are produced in the course of a research project. The "green" repository route is usually free, but relies on understanding of publishers' self-archiving policies that often require the deposit of an accepted manuscript of a paper, a version that authors don't tend to keep. With the onus of compliance placed on grant recipients, and with no centralized infrastructure in place to facilitate the process, it is not surprising that researchers often feel trapped between a rock and a hard place, and compliance levels remain low.

3 To streamline compliance for their authors, Canadian Science Publishing, an independent, not-for-profit publisher of over 20 science journals approached the 
University of Toronto Libraries with an idea of automated transfer and deposit of author manuscripts into the $\mathrm{U}$ of T's research repository, TSpace ${ }^{1}$.

This free service is available to authors publishing their papers in 21 CSP's NRC Research Press journals ${ }^{2}$ and only takes authors one click to opt into. The partnership was launched in April 2015 and makes over 1,200 manuscripts openly available annually.

\section{Workflow}

5 The manuscript transfer and deposit workflow developed by the UTL's Information Technology Services team in close consultation with CSP is outlined in Figure 1 (Maistrovskaya, Xiao Zhao, 2017) and the script is shared on Github under the Apache License 2.0 (University of Toronto Libraries, 2018).

6 The process is initiated by the author in the CSP's peer-review submission system, ScholarOne, opting into their manuscript being archived in TSpace. A zip file containing the accepted manuscript, supplementary files, and metadata in PubMed XML is transferred to the library's SCP server. UTL's Python script scans the directory on an hourly basis and extracts each package. Beautiful Soup 3 is used to parse the received metadata into Dublin Core. The script then prepares DSpace Simple Archive for each manuscript and uses the DSpace import API to upload content into a respective journal's collection. An ingestion report is generated at this point and emailed to the CSP and TSpace staff. Transferred zip files as well as prepared DSpace Simple Archive directories are backed up for quick re-ingestion if needed.

7 Upon ingest, the manuscript is immediately released for public access in the repository and assigned a permanent URL (handle) in addition to the publisher supplied DOI that points to the final version on the journal website. 
Figure 1. CSP-TSpace manuscript transfer and processing workflow (Maistrovskaya, Xiao Zhao, 2017)

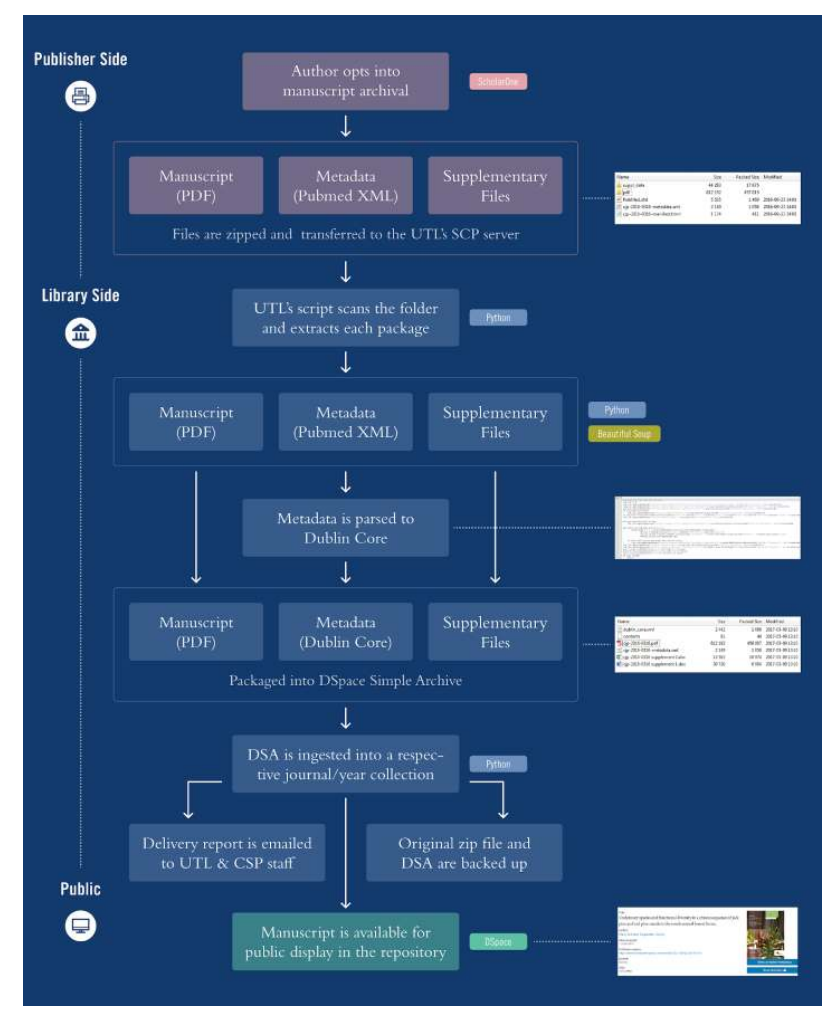

Available at http://hdl.handle.net/1807/80629

This work is licensed under a Creative Commons Attribution 4.0 International License.

\section{Challenges and opportunities}

8 Automated repository workflows have been around for a while and can be implemented using a variety of tools and protocols. A common challenge they share is that even a welldeveloped and robust workflow cannot do entirely without human intervention which affects its overall sustainability. In the SCP-UTL case, while the script takes care of package processing, metadata crosswalk, and ingest, human assistance is still needed on both ends of the pipeline with CSP staff creating and depositing the packages and UTL staff maintaining repository collections and troubleshooting technical issues. Such issues are uncommon, but while the vast majority of deposits go smoothly and entirely automatically, the script depends on the consistent structure of the transferred packages and metadata, and occasionally fails when encountering unexpected elements. One promising development that may help address this through a standardized framework is the Manuscript Exchange Common Approach (MECA) recently accepted to be developed as a NISO standard (NISO, 2018).

9 Apart from technical challenges, establishing a publisher-repository partnership demands commitment, trust, and mutual investment of time and effort-something that can only be initiated when both parties share common values and goals in public sharing and preservation of research. While funder mandates, such as Tri-Agency Open Access Policy (Government of Canada, 2015) or NIH Public Access Policy (U.S. Department of 
Health \& Human Services, 2016) have been a significant drive for these initiatives, our hope in sharing this workflow is to offer a fairly straightforward solution that can be implemented by small scale publishers and university presses looking to include green OA in their suite of services.

\section{Conclusion}

10 Making research openly accessible to the widest possible audience, and at the earliest possible opportunity has multiple benefits. Funded by Canadian federal grants, it makes the findings available to the public beyond journal subscriptions that are often limited to institutions and research organizations. Open availability of research benefits the authors and "science by accelerating dissemination and uptake of research findings" (Eysenbach, 2006, e157). It also facilitates societal advancement globally by "enabling researchers, scholars, clinicians, policymakers, private sector and not-for-profit organizations and the public to use and build on this knowledge." (Government of Canada, 2015).

11 Nonetheless compliance with funders' open access mandates remains challenging and complicated for many researchers, despite assistance available from their institutions in the form of consultations, institutional repository infrastructure, copyright support, and even mediated deposit services. As agreed by many Canadian institutional repository managers, one of the major stumbling blocks in streamlining compliance via the "green" route is getting hold of accepted manuscripts where publisher policy does not permit the deposit of a final article in a repository.

The automated manuscript deposit workflow removes the dependence on researchers keeping the ephemeral manuscript version. By transferring both the manuscript and accompanying metadata into a repository directly from the publisher's system, it makes compliance seamless and hassle free for grant recipients, and opens doors for further publisher-repository collaboration.

\section{BIBLIOGRAPHY}

\section{References}

Eysenbach, G. (2006, May 16). Citation advantage of open access articles. PLoS biology, 4(5), e157. https://doi.org/10.1371/journal.pbio.0040157

Government of Canada. (2015). Tri-Agency Open Access Policy on Publications. Retrieved from http:// www.science.gc.ca/eic/site/063.nsf/eng/h_F6765465.html

Maistrovskaya, M., Xiao Zhao, S. (2017, June). Publisher-Repository Partnership for Funder Mandate Compliance. Poster session presented at the Open Repositories 2017 conference, Brisbane. Retrieved from http://hdl.handle.net/1807/80629 
NISO. (2018, May 9). NISO Launches New Project to Facilitate Manuscript Exchange Across Systems.

[Press release]. Retrieved from https://www.niso.org/press-releases/2018/05/niso-launchesnew-project-facilitate-manuscript-exchange-across-systems

University of Toronto Libraries (2018, May). DSpace Simple Archives Importer. GitHub Repository. https://github.com/utlib/dspace_simple_archives_import

U.S. Department of Health \& Human Services. (2016, March 25). NIH Public Access Policy. Retrieved from https://publicaccess.nih.gov/policy.htm

\section{NOTES}

1. https://tspace.library.utoronto.ca/

2. https://tspace.library.utoronto.ca/handle/1807/67548

\section{ABSTRACTS}

In April of 2015, Canadian Science Publishing (CSP) in partnership with the University of Toronto Libraries launched an automated manuscript deposit service. Upon author's opt-in, an automated workflow transfers their accepted manuscript from the publisher system into the University of Toronto research repository, TSpace, where it is made openly available with a reference to the final version on the journal website. This free service is available to authors publishing their work in CSP's NRC Research Press journals and is of particular interest to grant recipients looking to comply with the Tri-Agency Open Access Policy on Publications that came into effect in 2015. This paper provides an overview of the partnership and the workflow that makes over 1,200 manuscripts openly available annually. It also shares the script that can be adopted by other libraries and publishers looking to provide automated deposit service to authors for the purpose of funder mandate compliance, green $\mathrm{OA}$, or preservation.

\section{INDEX}

Keywords: open access, funder mandate, automated deposit, accepted manuscript, institutional repository

\section{AUTHORS}

\section{MARIYA MAISTROVSKAYA}

University of Toronto Libraries, Canada

mariya.maistrovskaya@utoronto.ca

(corresponding author) 


\section{JUDY HUM-DELANEY}

Canadian Science Publishing, Canada

judy.hum-delaney@cdnsciencepub.com

(corresponding author) 